10.1590/S1414-40772018000300010

Este é um artigo publicado em acesso aberto sob uma licença Creative Commons

https://creativecommons.org/licenses/by-nc/4.0/

\title{
Universidade em tempos de precarização e incertezas
}

\author{
José Dias Sobrinho ${ }^{1}$
}

Resumo: A esperança dá sentido à educação. A esperança significa crença e expectativas na potencialidade de transcendência da situação histórica de cada ser humano e do conjunto da humanidade. A educação é o processo de formação humana pelo qual o indivíduo se obriga a superar algumas de suas imperfeições existenciais e sociais e visa transformar-se em um cidadão mais consistentemente equipado para a vida na sociedade. A educação é essencial, portanto, insubstituível. É um bem público, então, deve ser de qualidade para todos. A vida social e econômica demanda uma ampla formação de cidadãos-profissionais técnica e intelectualmente competentes e éticos. A sociedade atual naturalizou a incerteza e perdeu os sentidos e as referências da vida. É necessário promover ao máximo a ciência que beneficia a vida dos seres humanos. A educação de todos os níveis, particularmente a universidade e o sistema de ciência-tecnologia-inovação precisam recuperar seu papel público de formação humana. Precisam promover o conhecimento, o debate público e a autonomia de pensar para seguir abrindo de modo mais sustentável e informado os caminhos de uma sociedade plural, dinâmica e digna. A transcendência humana requer uma ampliação da consciência do homem no mundo.

Palavras-chave: Esperança. Educação pública. Formação humana. Universidade. Ciência.

\section{University in times of precariousness and uncertainties}

Resumo: Hope adds sense to education. Hope is the belief in and expectation towards the potential to transcend the historical situation of each human being and the whole of humankind. Education is the process of human formation through which individuals have to surpass some of their existential and social imperfections seeking to become a citizen who is more consistently equipped to live in society. Education is essential, and thus, it is irreplaceable. It is a public good, so it must hold quality for all. Social and economic living requires a broad formation for citizen-professionals, technically and intellectually competent, but also ethical. Today's society has naturalized uncertainty and lost sense and reference of life. There is a need to promote science that benefits the lives human beings. Education in all levels, particularly university education and the science-technology-innovation system need to claim back its formative, public role. They need to promote knowledge, public debate and autonomy of thought to keep creating sustainable ways to shape a plural, dynamic, dignified society. Human transcendency requires broadening human conscience.

Keywords: Hope. Public education. Human formation. University. Science. 
A educação só é possível porque existe a esperança. Todo processo educativo carrega uma chama de esperança de dias melhores, seja para os indivíduos, seja para a sociedade. A esperança significa crença e expectativas na potencialidade de transcendência da situação histórica de cada ser humano e do conjunto da humanidade. Está vinculada a aspectos positivos a se concretizarem mais adiante, intimamente associada às necessidades concretas e aos objetivos que se pretende alcançar. Tendo em vista as necessidades da vida real, valores guiam as perspectivas daquilo que se espera que se realize. Portanto, a esperança não é neutra ou desinteressada. Difere de uma a outra pessoa, de acordo com as circunstâncias e o cenário existencial concreto de cada um.

A esperança dá sentido à educação e anima os desejos e lutas por um futuro melhor. Alimentada pela esperança, a educação é um instrumento que pode conferir substância aos sonhos, dar sentido ao princípio da libertação humana, instituir o homem em sua busca natural de superação das indigências existenciais e sociais e dos anseios de ampliação da liberdade. Alicerça a formação moral e o desenvolvimento intelectual e social. Fornece as bases cognitivas, ético-morais, políticas e estéticas para a inserção e a participação consciente do indivíduo numa comunidade de comunicação e ação, numa cultura de tradições, disputas e consolidação de valores que identificam e constituem uma determinada formação societária. Enfim, ainda que jamais de modo plenamente satisfatório, ao fluir da história, pela educação o homem vem se capacitando a instituir o conhecimento e os saberes produzidos no processo civilizatório de superação da visão mágica da vida.

A educação é o processo de formação humana pelo qual o indivíduo solipsista e autorreferente se transforma em um cidadão mais equipado e mais consistentemente formado para a vida na sociedade. O outro é essencial para a existência de cada ser humano em particular. É na relação com a alteridade que se molda a subjetividade. É produzindo a própria existência situada na realidade social que se constitui o sujeito. A construção da subjetividade se realiza num ininterrupto processo de compreensão e transformação da realidade histórica em que cada um tem de produzir sua própria existência.

A convivência com o outro, a percepção de suas grandezas e seus limites, o discernimento sobre as maneiras de os membros de uma sociedade enfrentarem deveres e direitos, as interações dialógicas, feitas de amizade e conflitos, o reconhecimento das diferenças, dos antagonismos, das contradições e da pluralidade inerentes às sociedades humanas, a formação muitas vezes incerta e descontínua da autoconsciência, a assunção de 
responsabilidades e de opções axiológicas e políticas na vida pública vão construindo as subjetividades no correr da existência pessoal.

O ser humano é por natureza gregário. A produção de sua existência só pode ocorrer numa comunidade humana, com todos os seus problemas e contradições, e melhor realizada será quanto mais efetiva e solidária for sua inserção na sociedade. A formação de um indivíduo constitui-se também em uma ininterrupta ação sobre a realidade. Toda transformação humana é inseparavelmente transformação da vida em geral. A aceitação dessa ideia implica no reconhecimento da exigência da solidariedade, isto é, da responsabilidade compartilhada na produção do bem comum e de expansão da obra sempre inacabada de humanização em contraposição à barbárie.

A esperança carrega uma tensão entre a carência e a incerteza de solução. Igualmente, o futuro é imprevisível, mas há sempre a possibilidade de construí-lo melhor que o presente. É precisamente essa possibilidade sempre fomentada pelos sonhos e pela obra de emancipação que dá sentido à educação e, então, aos ideais de existência humana mais elevada e digna, vocacionada à liberdade, à igualdade social e à justiça. A educação precisa sustentar a recuperação da indestrutível capacidade humana de "sonhar um mundo no qual as barbaridades, o terror e o ódio são vencidos, e ganham a amizade, o civismo, a solidariedade e a justiça” (PETRELLA, 2005, p. 12). Sem os sonhos de desenvolvimento da civilização segundo os mais perenes valores humanos é praticamente impossível assegurar horizontes futuros mais favoráveis à evolução de sociedades emancipadas.

Atribuir um alto valor à educação como instrumento de promoção humana não significa, entretanto, desconhecer os seus limites e as trágicas realidades do mundo humano. É completamente descabida a crença num nirvana terrestre, puramente idílico e desgarrado da realidade, fruto de ilusões oníricas sem fundamento. Bem verdade que a fantasia é um lindo atributo humano, mas ela sozinha não supre sequer as necessidades mais comezinhas da vida de todo dia. Na vida corrente, todos enfrentam a bipolaridade hedonista da dor e do prazer, das tristezas e das alegrias, das violações de direitos e da justiça, da maldade e da bondade, do egoísmo exacerbado e da solidariedade, do autismo social e da interação convivial, dos medos e dos destemores, da apatia e do entusiasmo. Para a maioria dos indivíduos tende a ser prevalente o primeiro polo dessa ambivalência.

Esperança, sonhos, projetos e ideais de liberdade coexistem com as fragilidades, os desesperos e toda espécie de limitações da Humanidade. A educação há de ter consciência da miserabilidade da vida concreta, mas não menosprezar as grandes realizações humanas produzidas pelo gênio de notáveis indivíduos e também pela grandeza de milhões de pessoas 
que passaram e vivem despercebidas ao longo da história. A transcendência humana, tal qual a história, se desenha a cada instante da vida, obra de poucos gênios e, mais geralmente, de multidões de anônimos indivíduos em suas fainas diárias.

A educação assenta-se sobre um princípio fundamental: ela é essencial e, portanto, insubstituível. Não pode ser elidida, nem negligenciada, menos ainda substituída por outra coisa. É essencial e insubstituível como o ar puro, a água limpa, a ética, a moral, a alimentação sadia, a saúde, a moradia, a segurança, o trabalho decente e tudo o mais que é básico e imprescindível para uma vida humana digna e segura. A educação tem enorme centralidade em tudo o que se faça para a sustentabilidade deste mundo no presente e no futuro.

É preciso levar em conta que o valor moral de um princípio muito frequentemente é refutado pelos mais diferentes e contraditórios interesses dos diversos grupos sociais na vida cotidiana. Negar a educação a alguém é uma privação de um direito humano que põe em causa sua condição de cidadão ativo e potencialmente livre para os enfrentamentos públicos. É restringir-lhe o direito a participar plena e construtivamente da esfera pública, que é o território da vida social, do mundo do trabalho e do lazer, enfim, da política. É recusar-lhe a condição de membro legítimo de uma sociedade, de acordo com suas circunstâncias. O amesquinhamento de um indivíduo apequena a totalidade da humanidade. A violação de um direito humano, atingindo um ser humano em particular ou a amplas formações sociais, em última instância, empobrece a comunidade humana universal. Optar pela educação de qualidade significa escolher a civilização. Sonegá-la é optar pela barbárie.

A educação é um bem público, isto é, um princípio que existe como imperativo moral. Esse imperativo moral afirma que a dignidade humana deve ter sempre prioridade frente aos interesses individualistas. Que o bem comum prevalece sobre os interesses egoístas. A dignidade humana concebe o outro, assim também a humanidade toda, como um fim, não como meio para satisfações particulares. Sem a percepção do outro, um indivíduo não tem como se reconhecer. O ser humano é, por natureza, social. Não se pode separar o bem-estar individual do bem-estar da sociedade, pois ambos são interativos e coessenciais. Essa aliança relacional primária adquire, atualmente, novos contornos, porquanto vive-se hoje uma grave crise do conceito de comunidade.

Como tudo o que é público, educação é um direito de cada um e de todos. Direitodever, assim imbrincado, é constituinte da vida humana. Como qualquer outro direito humano, o bem comum depende do esforço e da cooperação de todos. Assim é com a sustentação das boas condições da vida humana, seja quanto ao respeito devido à preservação 
da natureza e de todas as condições e bases da vida, seja quanto à adesão aos valores e princípios do bem-viver coletivo. A ninguém é dado omitir-se ante as obrigações individuais e coletivas.

Todos somos corresponsáveis pelas melhorias dos processos civilizatórios. Como todo direito social e público, a garantia da oferta da educação, em quantidade e qualidade, e na medida do possível, é, basicamente, obrigação do Estado. O Estado vai muito além de eventuais ordenamentos governamentais. Ele incorpora as forças vivas da sociedade civil. $\mathrm{Na}$ oferta educacional, a administração central precisa contar com a indeclinável cooperação de todos cidadãos concernidos. A omissão de uns implica perdas de todos.

Deveres e direitos valem para as instâncias privadas e igualmente para as esferas públicas da vida. A realização pessoal e a criação de adequadas e sustentáveis condições do bem-viver coletivo é um direito e, correlativamente, um dever de cada um e de todos. Exigir um direito fundamental tem como contrapartida o dever de realizá-lo. A vida é recebida como um direito essencial, porém, inacabada e imperfeita. Edificá-la é árdua e permanente tarefa existencial da qual é impossível abdicar. E por ser imperfeita, requer a atuação incessante da educação.

A produção da vida não se restringe aos fenômenos físicos e materiais da vida. Bauman (2012, p. 27) alerta: “O Homo Sapiens destaca-se do resto da criação animal por ser indefinido e indeterminado, e, portanto, condenado à transcendência, a desafiar o status quo, a chegar 'acima' e 'além'”. Estamos condenados a assegurar nossa vida, pois, como lembra Gabriel García Márquez, "Os seres humanos não nascem de uma vez por todas no dia em que suas mães os dão à luz, senão que a vida os obriga a dar à luz a si mesmos" (GARCÍA MÁRQUEZ apud SAID, 2007, p. 111). É precisamente nosso inacabamento que nos oprime, mas também nos obriga a ir um para além da finitude. Fernando Pessoa (1999, p. 276) diz magistralmente: "O perfeito é o desumano, porque o humano é imperfeito".

Riscos e incertezas acompanham a vida de cada um. O ser humano é inacabado, imperfeito. Precisa produzir diuturnamente sua existência em meio a uma profusão de problemas físicos, sociais e espirituais. Imperfeito, mas perfectível. A construção da vida pessoal e social é impregnada de incertezas, caos, abismos e problemas de todo tipo, mas também de sonhos, projetos de superação, ideais de elevação e busca de transcendência.

Esperança, utopia, educação, Humanidade constituem um complexo semântico que tece a compulsão pela transcendência e pela busca da felicidade. A educação não pode tudo, mas sem ela a situação humana seria rasa e sem horizontes. Por outro lado, a educação aviva a 
esperança de superação da miserabilidade e fortalece os ideais de sublimação da dignidade humana.

O otimismo referente ao elevado valor da educação deve repelir a ingenuidade e a cegueira ante tantas vilanias no plano ético e extremas vulnerabilidades na vida pessoal e social de grande parte da população mundial. Ninguém escapa ao mundo das contradições e paradoxos humanos. Mesmo quando a vida das pessoas é animada pela esperança e pelos ideais de transcendência humana, ela está irremediável e permanentemente marcada pelas contingências da miséria, da opressão, das injustiças sociais e das ameaças de novos tipos de barbárie. Todos estão obrigados a produzir dignamente suas vidas, mas nem todos possuem as condições mais apropriadas para essa tarefa humana.

Sempre houve discórdias, ódios e guerras. Só que as guerras de hoje são uma indústria que produz e utiliza o estágio mais avançado e sofisticado da tecnologia. Somas vultosas de dinheiro são destinadas a pesquisas de finalidades bélicas. A barbárie se modernizou e naturalizou o terror e a matança em grande escala. É como se fome, ódio, conflitos e matança, hoje globalizados, fossem proeminentes indicadores de sucesso humano. "A matança em massa se tornou o feito máximo da civilização” (2004, p. 84), diz Galbraith. Talvez seja verdade que quanto mais poderoso é um país no tabuleiro dos conflitos globais, mais sua sociedade é moralmente doentia e autodestrutiva, mais a percepção do outro é aniquilada, mais o indivíduo autorreferente se concebe plenipotenciário.

Além dos conflitos e guerras entre potências globais, também há um outro tipo de barbárie. Uma insidiosa barbárie vai minando a solidariedade e a boa convivência das pessoas na vida corrente. Fomenta cada vez mais a concentração de rendas, as divisões entre ricos e pobres, a brutal desigualdade que viola direitos e rompe as escassas possibilidades de harmonia na sociedade. São barbarias vistas como naturais, tão frequentes são elas. Violências e inseguranças estão irremediavelmente impressas na alma das sociedades e das pessoas. Já arraigadas tão naturalmente à vida de cada dia que pouco espanto causa às pessoas a prevalência de preconceitos, assimetrias, desajustes, autoritarismos, opressões, nefandos abismos sociais.

A educação inerente às rotinas de todas as pessoas, famílias, associações, escolas e, enfim, do coletivo social e do universo político, é um dos mais importantes e eficazes contrapontos à finitude e à fragilidade humana. Tratar com otimismo a educação é crer na potencialidade de impulsionar a dignificação da vida humana. A teoria e a prática da educação exigem compreender, ainda que muito limitadamente, os dilemas e paradoxos existenciais e 
as contradições dos processos societários. Com otimismo e esperança, mas sem elidir as fragilidades, infortúnios e vilezas da condição humana.

A educação é um bem público e direito humano e social. A universidade, assim como o conjunto de instituições educacionais, é um patrimônio de toda a sociedade. Não pertence ao universo dos negócios e dos interesses privados e egoístas. Suas finalidades não são negociáveis, como o são os produtos e serviços dos diversos setores da economia, destinados exclusivamente ao lucro. Isto não significa que seja terra de ninguém, cativa de todo e qualquer tipo de exploração mercantilista.

O Estado não tem capacidade para atender toda a demanda por educação. O setor privado sempre visa o lucro, em primeiro lugar. Mas, em educação, o lucro não pode ser o objetivo único a beneficiar os proprietários individuais, embora seja perfeitamente aceitável desde que regido por normas legalmente regulamentadas. As instituições privadas do setor educativo também estão obrigadas a cumprir os compromissos públicos e a submeter-se à supervisão normativa do Estado. A educação privada também deve orientar-se pelas premissas do bem comum. Também lhe incumbe formar cidadãos-profissionais com grande capacitação técnica, sentido de liderança, inclinação à inovação e ao empreendedorismo e, de modo especial, ao desenvolvimento da capacidade de entender e de colaborar para a construção do mundo humano. Portanto, é perfeitamente legítima e necessária a participação de entidades privadas na oferta de educação, sempre e quando elas cumprem os compromissos de formação da cidadania e promoção do bem social.

Mediante os conhecimentos, técnicas e a vivência de valores humanos essenciais, a universidade deveria agir para fornecer as bases de uma economia voltada ao desenvolvimento humano e ao fortalecimento das identidades nacionais. Economia não deve ter como limite o lucro das empresas e o enriquecimento escandaloso de empresários, nem só deve ser movida pela obsessão da competitividade. Ocorre que a economia destes tempos é caracterizada por monopólios, nefasta concentração de renda e enorme desigualdade social. Os poderosos do mercado exigem uma formação profissional que favoreça o crescimento do capital, pouco ou nada se preocupando com os valores da equidade e da solidariedade, ou seja, da responsabilidade compartilhada.

Esse imperativo do mercado determinado pelas gigantescas corporações multilaterais coloca em risco o cumprimento das finalidades essenciais que justificam a existência da universidade como instituição pública de formação humana. Em plena globalização, o ensino superior pouco se interessa pelo desenvolvimento humano ou pela formação de uma cidadania informada e cônscia de suas responsabilidades na sociedade. Salvo as honrosas e muito dignas 
exceções, mais the atrai o aumento dos lucros obtidos nos serviços prestados e nos produtos vendáveis. Bilhões de dólares circulam no ensino superior global e a tendência é de crescimento, pois a demanda de mais educação aumenta exponencialmente nos últimos anos. Além do crescimento quantitativo, vale acrescentar que as respostas locais serão diferenciadas, conforme as realidades de cada país e região. Cabe observar que, em países de economia vulnerável, muitos jovens não se animam a ter uma escolaridade regular. Nesses casos, proliferam multidões de jovens que não trabalham, nem estudam, muito menos participam de qualquer iniciativa social positiva e são graves e onerosos problemas para o Estado e a sociedade civil. Nessas condições, não há muito a esperar da consolidação de um país nas próximas décadas, pois não se contará com a participação produtiva e proativa de importante parte da atual geração.

Distintas são a lógica e as leis da economia de mercado. Nas empresas sem comprometimentos sociais, busca-se otimizar os lucros, a ganância, os proveitos individuais, o enriquecimento material ilimitado, não importando, muitas vezes, os conteúdos e formas de alcançá-los. As empresas que são obsessivamente movidas pelo objetivo da acumulação sem limites têm o lucro como última fronteira. Na lógica empresarial ultraliberal, o espírito de competitividade é de grande valia e deveria ser fortemente exercitada inclusive pelos atores educacionais. A universidade teria a função primordial de aumentar a competitividade na relação capital-capital (concorrências entre os capitalistas) e na relação capital-trabalho (entre patrão e empregados). Ser competitivo, nessa lógica, é querer sempre estar à frente e acima dos outros. Mais educado seria, então, o mais competitivo, como se fossem iguais e justas para todos as condições de partida e as circunstâncias ao longo da vida. A noção de qualidade educativa perde seu sentido de bem público.

O fortalecimento do setor produtivo seria também de grande importância para a inserção das empresas na economia mundial. Os motores desse desenvolvimento econômico pelo aumento da competitividade das empresas seriam o conhecimento, fruto dos novos modos de produção, e as competências e habilidades propiciadas pela universidade, segundo a lógica mercantilista da economia globalizada. Nesse caso, seguindo essa lógica, a universidade deixaria de ser um patrimônio da sociedade civil, e nem lhe caberia necessariamente a formação integral de pessoas moralmente honradas e de cidadãos conscientes de seu papel na promoção de valores materiais e imateriais que beneficiam toda a sociedade.

Hoje, não há propriamente uma crise da economia, ideia ampla e ingenuamente aceita e incorporada pela maioria da população, e, sim, uma real e brutal desigualdade social 
conscientemente engendrada pelos poderes hegemônicos. O mundo da globalização está acometido de profunda confusão de sentidos. Bauman (1999, p. 67) apresenta importante crítica: "O significado mais profundo transmitido pela ideia de globalização é o do conteúdo indeterminado, indisciplinado e de autopropulsão dos assuntos mundiais; a ausência de um centro, de um painel de controle, de uma comissão diretora, de um gabinete administrativo". Riccardo Petrella (1997, p. 17) acrescenta alguns elementos: “A globalização arrasta as economias para a produção do efêmero, do volátil (por meio de uma redução em massa e universal da durabilidade dos produtos e serviços) e do precário (empregos temporários, flexíveis, de meio expediente)".

A universidade não deve coonestar e reproduzir os mecanismos econômicos e políticos que esgarçam as relações nas sociedades mediante o aprofundamento da absurda concentração de rendas e poderes A educação tem a missão de formar pessoas honradas, elevadas intelectual e moralmente, cidadãos bem equipados para o exercício consciente das profissões e da cidadania. Cidadania é a inserção consciente e ativa dos indivíduos na vida da Cidade (Polis), isto é, em termos modernos, da participação política, crítica e consciente nos projetos e sonhos de consolidação da Pátria e da Humanidade. Ninguém escapa ao mundo das contradições e paradoxos humanos. Mesmo quando a vida das pessoas é guiada pela esperança e pelos ideais de transcendência humana, ela está irremediável e permanentemente marcada pelas contingências da miséria, das injustiças sociais e das ameaças de novos tipos de barbárie.

Em conformidade com os princípios e compromissos de realização dos interesses sociais relativamente ao bem-viver coletivo, as instituições privadas poderão muito bem integrar-se ao sistema educacional nacional. Isso é não só desejável. É necessário. Certamente há espaços e necessidades sociais para a participação de instituições privadas que, para além de legítimos ganhos financeiros, instaurem processos educacionais em acordo com os projetos de elevação dos indivíduos e da sociedade.

O inaceitável é a instauração, nas estruturas educacionais, de mecanismos exclusivamente de lucro e restritamente de mais valia, em detrimento do sentido público da educação. Não há possibilidade de se construir um futuro a médio e a longo prazo se a educação, a formação, o conhecimento e, especialmente, o complexo ciência-tecnologiainovação forem exclusivamente um mecanismo para as empresas exorbitarem seus ganhos financeiros, eximindo-se de quaisquer compromissos com o desenvolvimento sustentável da vida no planeta que a todos cumpre cuidar. 
Como todo bem público, a educação há de ser o quanto possível de qualidade, não apenas para setores sociais já privilegiados, mas para todos. A bem dizer, por uma questão de justiça e equidade, são os indivíduos mais vulneráveis e tradicionalmente desprotegidos os que mais merecem uma educação escolar de qualidade, pois eles não possuem muitas oportunidades para complementar o desenvolvimento intelectual em outros circuitos culturais para além das disciplinas curriculares. Isso impõe a exigência de o sistema educacional de ser acessível a todos. O sistema deve ser democrático e proporcionar uma oferta de oportunidades educacionais suficientemente amplas e plurais, em consonância com as demandas prioritárias das formações sociais, da cidadania e da construção da nação.

Não bastam, portanto, as possibilidades de acesso. É necessário e justo que a inclusão de indivíduos socialmente desprotegidos seja sustentada por iniciativas que lhes garantam as adequadas condições de estudo e de vida escolar. Indivíduos e grupos socialmente vulneráveis e marginalizados ao longo da história precisam ter o necessário apoio para poderem mais dignamente se realizarem como seres humanos. Isso é importante não apenas desde um ponto de vista moral, mas também de sobrevivência nas disputas e competições da vida pública, especialmente no mundo imposto pelo mercado. Precisam ter condições o quanto possível mais igualitárias para competir com jovens de classes sociais privilegiadas e inserir-se condignamente no mundo do trabalho, nas instâncias de poder e da cidadania em geral.

O sistema econômico não pode ser o centro e a finalidade exclusiva da vida humana, não lhe cabe determinar as formas de organização social e, principalmente, nenhuma razão lhe assiste em arvorar-se a salvação da humanidade. Ao contrário, o sistema econômico universalmente prevalente, em grande escala e em boa medida, tem que ser responsabilizado pelo défice de moralidade e pela destruição dos ideais de justiça, equidade, igualdade e solidariedade mundo afora.

Sem educação de alta qualidade e francamente disponibilizada, são quase totalmente nulas as possibilidades de edificação de uma nação forte, constituída de cidadãos conscientes e de ampla visão de mundo. Não se trata de mera questão estatística. Não são os números de diplomados e outros indicadores os únicos critérios para avaliar o bom ou o mau funcionamento da educação. A finalidade essencial da educação é a formação, em sentido pleno. Além da capacidade de refletir sobre as questões mais cruciais do mundo, a formação integral dos indivíduos inclui, necessariamente, uma consistente formação técnica e profissional, inextricavelmente sustentada na ética e nos projetos e sonhos das pessoas e da nação. 
A educação deve cumprir os objetivos de formação de sujeitos sociais conscientes de seus papeis na vida pública. Isso implica uma formação de cidadãos-profissionais técnica e intelectualmente competentes e éticos. Hoje, em razão da grande volatilidade dos conhecimentos e da necessidade de constante adaptação do capital e do trabalho, é necessária uma forte formação da inteligência.

Formação cidadã e formação profissional são correlativas e coessenciais nos processos de constituição de sujeitos sociais orientados pelos imperativos morais do bem comum. Petrella afirma, com muita propriedade, que as instituições de educação não existem para preparar os novos conquistadores do mundo, mas para formar cidadãos. "Se as universidades não estão preparadas para ensinar isso, nenhum espanto se a injustiça, a violência, a guerra, permaneçam no futuro as formas naturais de comportamento dos humanos" (PETRELLA, 1997, p. 134).

Os indivíduos buscam na educação os benefícios que lhes possam proporcionar bons empregos, melhores oportunidades e situações sociais, potencializar suas condições financeiras e assegurar-lhes uma vida digna e produtiva. Isso é bastante legítimo, necessário e naturalmente humano, não apenas para cada indivíduo e para seu grupo familiar, mas também imprescindível para o fortalecimento das estruturas da nacionalidade, sempre e quando se exercitam em conformidade com as normas gerais e os valores da ética, da moral e dos processos de elevação da humanidade. Trata-se, portanto, de aprofundar a formação técnica e ético-moral de cidadãos-profissionais, isto é, equipar profissionais com amplos, apropriados e atualizados conhecimentos a sustentar o exercício da cidadania bem informado.

O progresso material, desde que assentado em valores humanos de dignidade e respeito ao bem comum, é um dos objetivos alavancados pelas aspirações e projetos das pessoas. Sem o desenvolvimento técnico-profissional, submetido à ética e à moralidade públicas, são escassas as possiblidades de existência de indivíduos plenamente realizados, de sociedades multidimensionalmente evoluídas e de um país solidamente sustentável.

A universidade não pode ser instrumento de regressões e destruições. Ao contrário, como uma instituição do conhecimento, juntamente com a formação integral dos jovens, compete-lhe preservar a natureza, que é patrimônio de todos e da qual todos fazem parte, como bem inalienável e fundamental para a vida humana. Obviamente, o espetacular domínio técnico-científico impulsionado pela informação, impõe a necessidade de profissionais com grande capacidade de adaptação às rápidas transformações do mundo econômico e cultural e com a mente sempre disposta à aprendizagem permanente de conhecimentos novos, inovadores e em constante movimento e volatilidade. 
A popularização mundial de alguns instrumentos de comunicação, que faz parte da "sociedade da informação", é frequentemente designada pela expressão "sociedade do conhecimento". Essa é uma simplificação perigosa. A chamada "sociedade do conhecimento" atual não corresponde aos anseios de uma humanidade democrática, culta e justa, na qual o conhecimento seria patrimônio de todos e superaria obstáculos ao impulsionar o desenvolvimento humano e a qualidade da vida social em suas diversas dimensões. Isso não se realizou. Juntamente com indiscutíveis benefícios gerados na sociedade universal pelo sistema de informação, também proliferam grandes malefícios.

Numa autêntica sociedade do conhecimento, a ciência, a tecnologia, a inovação e a informação não deveriam estar somente a serviço de minorias. Alcançaria a todos. Mas a proclamada sociedade do conhecimento vigente ainda não realizou o que prometeu e o que a seu respeito se divulga com ingenuidade e otimismo. O conjunto amplo e diversificado de instrumentos e equipamentos de informação promove um rápido progresso nas esferas econômicas e financeiras das camadas ricas, geralmente, em detrimento dos valores da subjetividade e das condições básicas de vida coletiva saudável e realmente sustentável.

A universidade deve empenhar-se, de acordo com seus limites e possibilidades, ao desenvolvimento econômico, não em uma perspectiva economicista, porém como instrumento de humanização. É preciso questionar os conceitos vulgarizados de desenvolvimento e de progresso. Os critérios e indicadores econômicos não devem ser tomados como os únicos definidores do desenvolvimento ou do progresso. Desenvolvimento econômico desenraizado da complexidade das dimensões da vida humana é cego e iníquo. O desenvolvimento e o progresso são, antes de tudo, evolução de todas as dimensões do ser humano na trajetória das tarefas civilizatórias. O necessário e desejável aumento de produtividade e renovação das estruturas das dimensões materiais da sociedade há de ser fator de mais equidade e justiça social, e não de rupturas sociais.

É imperioso evitar que o progresso material ocorra destruindo as fontes da natureza que tornam possível a vida humana com boa qualidade. Isso exige ação, pensamento e vontade de um conjunto privilegiado dos atores mais qualificados da sociedade, como é o caso dos intelectuais e dos gestores públicos. Isso requer ciência e consciência. Estamos falando de práxis a ser exercida pelos "intelectuais e acadêmicos que desejam saber o que estão fazendo, com o que estão comprometidos como eruditos, e que também desejam conectar esses princípios ao mundo em que vivem como cidadãos" (SAID, 2007, p. 25). Isso impõe à práxis científica adotar "a crítica de seu autoentendimento histórico" e, "através de alterações em sua autoimagem e em sua configuração política, introduzir freios e contrapesos 
no 'desgoverno' do avanço científico-tecnológico, atualmente em desabalada e explosiva carreira" (BECK, 2011, p. 273).

A implicação é uma característica essencial da universidade. Dizer que a atividade intelectual deve implicar não significa que deva complicar. Significa que a implicação abre perspectivas de diversidades e novos horizontes de compreensão. A crítica fundamentada e o debate fecundo são o cerne da implicação e a seiva da universidade. Sem a circulação de ideias, sem debates e sem crítica, a universidade se amesquinha e falha na incumbência de pensar a sociedade e oferecer-lhe soluções. Abdica de sua natureza de espaço institucionalizado de produção cultural, do pensamento crítico e da formação fecunda para o exercício da cidadania. A inserção social é fundamental para a formação do ser humano. "Tornar-se um ser humano consiste em participar em processos sociais compartilhados, nos quais emergem significados, sentidos, coordenações e conflitos”, diz Schinitman (1996, p. 17, apud VIAL, 2001).

Ser cidadão é participar de modo responsável e informado nos processos sociais de constituição da vida política. É preciso dialogar para conhecer mais amplamente. É preciso conhecer para que as transformações sejam mais consistentes. É preciso promover o conhecimento, o debate público e a autonomia de pensar para seguir abrindo de modo mais sustentável e informado os caminhos de uma sociedade plural, dinâmica e mais humana. Tudo isso se contém na solidariedade, que é precisamente a corresponsabilidade de todos na construção do bem comum.

Há riscos de grande monta na ciência que se põe a serviço da economia de mercado. Os principais riscos advêm de sua subserviência ao neoliberalismo. Necessário, portanto, instaurar alguns freios ao mau uso da ciência, embora isso ainda seja pouco eficiente ante a hegemonia neoliberal. Necessário promover ao máximo a ciência que beneficia a vida dos homens, das mulheres e crianças de todas as categorias. A grande maioria da população requer muito mais e muito melhores atendimentos de saúde, alimentação, saneamento, lazer etc.

É preciso sempre lembrar que a ciência não é neutra e desinteressada. Todo conhecimento e toda ação se passam no conviver humano em uma determinada cultura e expressam visões de mundo e desejos de seus atores. No solo da realidade vivida no cotidiano universitário, o debate público e a crítica bem fundada são importantes não só para aportar novos conhecimentos e orientar possíveis ações, mas, também, para aclarar alguns dos interesses explícitos ou ocultos dos diferentes atores e grupos. A vitalidade intelectual em ato anima o fluir do cotidiano universitário. 
É preciso revitalizar o humanismo. Mas que seja um humanismo construído no solo das vicissitudes do real, não um presente definitivo dado por uma transcendência externa. É no universo multiverso de cada dia que se tecem as teias da vida real. Em meio às vicissitudes, nos fluxos e refluxos da vida, é que bem ou mal se desenvolvem os fenômenos da cultivação da humanidade. Humanismo é cultivo da construção da civilização humana em suas mais amplas e profundas dimensões. É a imprescindível tarefa de superação de fragilidades e de elevação humana, diligência contínua e obrigatória na perspectiva de ir além e mais alto, com suporte e motor do conhecimento e a bússola da ética.

O ato de cultivar a humanidade cumpre a todos. Cada ser humano é sempre situado, datado e imerso numa cultura onde produz sua vida em contato com os outros. $\mathrm{O}$ indivíduo não vive fora de um conjunto multiverso de atividades, símbolos, crenças, saberes e valores que conferem alguma identidade ao grupo humano do qual participa. A cultura distingue um grupo de outro. Não é estática e nem se desliga dos horizontes do viver. Ela requer o processo ativo e contínuo de cultivo da humanidade. Desse processo, cada um de nós é obrigatoriamente protagonista, independentemente de suas condições pessoais e circunstanciais.

Certamente há poderosas forças contrárias a enfrentar. Provém principalmente do poder político e ideológico que o mercado impõe à sociedade. Com grande proeminência dentre as demais instituições, à universidade se colocam enormes desafios e encruzilhadas. Não bastassem a explosão e a fragmentação dos conhecimentos a serem produzidos e ensinados, num cenário de novos modos de produção, bem como as novas relações e modalidades de ensino e aprendizagem, a universidade destes tempos se depara com as múltiplas e diferentes exigências da competitividade, da naturalização dos processos de privatização geral em detrimento do Estado nacional, de questões relativas à transnacionalização e à internacionalização, às leis e a critérios internacionais, de inserção no mundo globalizado, da consolidação da democracia, da equidade e da justiça social, da produção de ciência e tecnologia para atender distintas demandas, da formação de cidadãos conscientes e participativos, de prestação de serviços de toda ordem à comunidade, de desenvolver atitudes propícias à educação permanente e à aprendizagem contínua, de fomentar os valores da boa convivência e de impulsionar a promoção do desenvolvimento econômico-social.

Há instrumentos suficientes para tratar a questão da cobertura educacional. Esses instrumentos e estudos expõem ao público os números e estatísticas referentes à quantidade de estudantes, professores, produtos de pesquisa, publicações, recursos orçamentários etc. Desde 
que sigam corretas metodologias, as elaborações quantitativas oferecem informações que podem ser úteis aos administradores, políticos, empresários e estudantes.

Há desafios praticamente insuperáveis devidas ao fato de que a educação é um campo atravessado de interesses contraditórios e em permanentes disputas pelos distintos grupos de interesses e pelas diferentes aspirações individuais. As questões técnicas são mais susceptíveis a enquadramentos razoavelmente comuns, desde que apoiadas em conhecimentos atualizados. Restam mais complexos os entendimentos que envolvem valores e visões de mundo distintos e contraditórios das comunidades e do próprio Estado.

Diz Boaventura de Sousa Santos (2004, p. 100) que a democratização externa se confunde com a responsabilização social da universidade. Para ele, “o que está em causa é a criação de um vínculo político orgânico entre a universidade e a sociedade que ponha fim ao isolamento da universidade". Mas a universidade deve cuidar para não atentar contra sua própria natureza de instituição de formação. Se ela passa a adquirir um estatuto operacional de capacitação de competências fragmentárias e de aplicação imediatista, "o conjunto da sociedade perde seu último lugar institucional de síntese e de orientação crítica" (FREITAG, 1995, p. 30).

São de extraordinária complexidade as disputas políticas e ideológicas a respeito da educação, especialmente a de nível superior. Isso faz parte da sinergia entre a economia neoliberal informacional e a noção vigente de progresso material da sociedade, o que torna a educação, especialmente a de nível superior, um campo de alta relevância como motor do desenvolvimento econômico em todo o mundo. As contradições de caráter social não são simples. Há um estreito entrelaçamento de caráter epistemológico, econômico, político, ideológico, moral e, sobretudo, filosófico.

Não há consensos amplos e informados sobre algumas das principais missões da universidade. Em uma visão humanística, certamente lhe cumpre cultivar os saberes, elevar a qualificação dos cidadãos que atuam nos ambientes de sua abrangência e, ainda mais complexo, fazer-se referência moral e política para as tarefas civilizatórias, acolher a pluralidade humana e atribuir significados aos conflitos e dissensos dos diferentes grupos humanos e seus diversificados projetos coletivos e existenciais. De todo modo, se é verdade que a universidade deve elevar-se a planos mais altos para construir sínteses e visões de conjunto das transformações globais, mais necessário ainda que ela não se desgarre das realidades do viver humano no chão que naturalmente pisamos, mesmo naqueles dias aparentemente anódinos, tolos e sem história. 
Há, portanto, sérias divergências, dificuldades e limitações conceituais que tornam impossível qualquer definição de qualidade que seja universalmente aceitável e sustentável por muito tempo. Entretanto, juntamente com a pertinência e a relevância, dentre muitos outros, alguns critérios podem ser considerados fundamentais, como a equidade e a responsabilidade social das instituições nos respectivos campos de diversidades culturais e de objetivos políticos específicos. A qualidade não é uma entidade desenraizada. Ao contrário, ela deve estar ineludivelmente vinculada às finalidades sociais da sociedade a que pertence. Ou seja, a qualidade se insere nos compromissos públicos e nos papeis sociais de cada instituição, embora, desgraçadamente, ela hoje esteja sendo deslocada ao mundo do comércio e dos lucros privados.

A formação humana se constitui de conhecimentos, de ciência e técnica, e também de valores. A práxis sem a moral e a ética é desnorteada e cega. Não se trata de processo pacífico, pois a conflitualidade é inerente à natureza social humana. Para evoluir culturalmente, toda sociedade precisa desenvolver estruturas sólidas não apenas de ciência, mas, sobretudo, de moral. Bento (2012, p. 41) sintetiza a pauta: "As sociedades somente são moralmente aceitáveis se não assentarem na desigualdade intencional. Mais, somente são eficientes se forem equitativas. E, ainda, os cidadãos somente são livres se forem minimamente iguais". Isso se coaduna com palavras de Petrella (2005, p. 224): "O mais importante para os seres humanos não é aprender a sobreviver, a ser melhores, os mais competitivos, senão aprender a viver juntos".

A crise civilizacional de nossos dias se caracteriza pela deterioração do sistema social e guarda estreita relação com a crise do ecossistema. Antes que seja tarde demais, parece serem urgentes e prioritárias profundas mudanças de sentido ético, político e econômico, uma nova cultura humana que realmente cuide do planeta terra como a casa comum de todos. As dificuldades são gigantescas, pois se trata de agir sobre modelos de vida humana perversos e profundamente arraigados na história de conflitos, destruições e cultivos do ódio levados ao extremo pelo neoliberalismo.

Cerca de 500 grandes corporações no mundo determinam como deve ser a vida de bilhões de indivíduos que hoje vivem e sofrem as ações deletérias, da escandalosa concentração de rendas, destruição de empregos e submissão moral. A economia neoliberal cria conflitos, desemprego, esgarçamento social, ódio, violência e relativização do valor humano. Não lhe interessa a promoção de um desenvolvimento democrático, menos desigual e mais sustentável. Para ela, só tem lugar o Estado Mínimo. Mas, como se sabe, esse Estado é Mínimo para a imensa maioria de pobres e vulneráveis, e é Máximo para uma restrita classe 
de endinheirados e supostos donos do mundo, graças ao poder que lhes dá o inescrupuloso acúmulo de riquezas.

A concentração de riquezas materiais e imateriais e a consequente pobreza são globais. A pobreza, diz Milton Santos (2000, p. 72) é "politicamente produzida pelos atores globais com a colaboração consciente dos governos nacionais [...] com a conivência dos intelectuais contratados - ou apenas contatados - para naturalizar essa naturalização”, Contudo, ele deixa entreaberta a porta da esperança: "não há apenas um caminho e este não é obrigatoriamente o da passividade" (2000, p. 78).

A superação desse quadro passa, portanto, pela improvável derrocada do neoliberalismo. Derrocada improvável, dada a capacidade de renovação do capitalismo, mas, dentro dos possíveis humanos. Em todo caso, é visível a grave crise do capitalismo atual. Mas entenda-se corretamente: o nome verdadeiro dessa crise é desigualdade. Quanto maior a desigualdade, maior é a dificuldade de a economia de mercado resolver problemas que ela mesma gestou e realimentou: desemprego, fome, guerras, graves conflitos entre nações, matança generalizada, degradação moral... A tecnologia, instrumento principal da economia de mercado, prometeu uma vida cada vez mais próspera, feliz e inclusiva, e realmente isso ocorreu para uma elite global, mas também ajudou a gerar uma sociedade partida, desorientada, odienta e ameaçada pelos riscos reais dos obscurantismos e da barbárie. Em relação à tecnologia não se deve ser nem deslumbrados, nem luditas.

Vivemos em uma sociedade que naturalizou a incerteza e perdeu os sentidos e as referências da vida. Mas não podemos lavar as mãos como se não tivéssemos nenhuma responsabilidade por esses descaminhos, errâncias e ofuscamento dos horizontes. A edificação da humanidade a que cada um deve comprometer-se e, em correlação dialética, a realização da humanidade em cada indivíduo requer a recuperação dos valores que dão sentido e orientação à vida pessoal e social. A promoção humana se realiza promovendo, simultaneamente, uma ampliação da consciência do homem no mundo. Trata-se de processo essencial, porquanto "viver na incerteza é traumático. Viver na incerteza dos sentidos e dos valores é pior, pois que estes sintomas emergirão e reemergirão continuamente" (HELLER, 1999, p. 21). 


\section{Referências}

BAUMAN, Zygmunt. Globalização: as consequências humanas. Rio de Janeiro: Zahar, 1999. BAUMAN, Zigmunt. Sobre educação e juventude: conversas com Ricardo Mazzeo. Rio de Janeiro: Zahar, 2012.

BECK, Ulrich. Sociedade de risco: rumo a uma outra modernidade. 2. ed. São Paulo: Ed. 34, 2011.

BENTO, Jorge Olímpio. Corrida contra o tempo: posições e intervenções. Campinas: Editora da Unicamp, 2012.

FREITAG, Michel. Le naufrage de l'Université et autres essais d'épistémologie politique. Québec: Nuit Blanche Éditeur; Paris: Éditions La Découverte, 1995.

GALBRAITH, John Kenneth. A economia das fraudes inocentes: verdades para o nosso tempo. São Paulo: Cia. das Letras, 2004.

HELLER, Agnes. Uma crise global da civilização. In: A CRISE dos paradigmas em ciências sociais e os desafios para o século XXI. Rio de Janeiro: Contraponto, 1999.

PESSOA, Fernando. Livro do desassossego. São Paulo: Cia. das Letras, 1999.

PETRELLA, Riccardo. Une machine infernale. Le monde Diplomatique, jun. 1997.

PETRELLA, Riccardo. El derecho a doñar. Propuestas para una sociedad más humana. Barcelona: Intermón Oxfam, 2005.

SAID, Edward W. Humanismo e crítica democrática. São Paulo: Cia das Letras, 2007.

SANTOS, Milton. Por uma outra globalização: do pensamento único à consciência universal. Rio de Janeiro: Record, 2000.

SOUSA SANTOS, Boaventura. A Universidade no Século XXI: para uma reforma democrática e emancipatória da Universidade. São Paulo: Cortez, 2004.

VIAL, M. Se former pour évaluer: se donner une problématique et élaborer des concepts. Bruxelles: De Boeck Université, 2001.

${ }^{1}$ José Dias Sobrinho

${ }^{1}$ Pesquisador Autônomo | Universidade Estadual de Campinas | Campinas | SP | Brasil. Contato: jdiassob@gmail.com

ORCID (iD) https://orcid.org/0000-0001-5077-7764 